\title{
Optimal Design of a Hybrid Membrane System Combining Reverse and Forward Osmosis for Seawater Desalination
}

\author{
Raquel Salcedo-Diaz*, Ruben Ruiz-Femenia, Jose A. Caballero \\ Department of Chemical Engineering, University of Alicate. Ap. Correos 99, E-03080, \\ Alicante, Spain. \\ raquel.salcedo@ua.es
}

\begin{abstract}
In this work we study Forward Osmosis (FO) as an emerging desalination technology, and its capability to replace totally or partially Reverse Osmosis (RO) in order to reduce the great amount of energy required in the current desalination plants. For this purpose, we propose a superstructure that includes both membrane based desalination technologies, allowing the selection of only one of the technologies or a combination of both of them seeking for the optimal configuration of the network. The optimization problem is solved for a seawater desalination plant with a given fresh water production. The results obtained show that the optimal solution combines both desalination technologies to reduce not only the energy consumption but also the total cost of the desalination process in comparison with the same plant but operating only with RO.
\end{abstract}

Keywords: optimal design, seawater desalination, emerging membrane technologies, forward osmosis.

\section{Introduction}

Clean water scarcity is affecting over one third of the world's population. As $97 \%$ of all the water on the planet is saline, desalination has gained wider interest in the last decades. Reverse Osmosis (RO) is currently the most widely used desalination technology. However, RO is an energy-intensive process because of the high pressure required, especially for seawater desalination (60-70 bar). This main drawback of the RO not only makes this technology energy availability and cost dependent, but also produces a great amount of global warming emissions. The energy required for the seawater RO is $2.5-4 \mathrm{kWh} / \mathrm{m}^{3}$, which translates into $3 \mathrm{~kg}$ of $\mathrm{CO}_{2} / \mathrm{m}^{3}$ of water treated (Nirmalakhandan et al., 2010). This high energy consumption joint with the growing environmental concerns is promoting the development of alternative environmentally friendly technologies. In the last few years, Forward Osmosis (FO) has emerged as an alternative membrane technology for water purification and desalination (Chung et al., 2012a). FO is a natural osmosis-driven process involving a semipermeable membrane and a draw solution. The draw solution has a higher osmotic pressure and is able to extract water from the feed solution. The main advantage of FO is that it operates at no hydraulic pressures which has resulted in rapidly growing interests in it from various disciplines, being one of them seawater desalination. FO based seawater desalination involves at least two steps: extraction of water from the seawater by a draw solution and separation of the product water from the diluted draw solution by means of other membrane separation processes (RO, Ultrafiltration (UF), Nanofiltration (NF)) or thermal methods (distillation). However, there are still some challenges that must be 
overcome to bring FO to commercialization. Currently, one of the major challenges of FO technologies is the lack of draw solutes that can be easily recycled (Chung et al., 2012b). Therefore, remarkable efforts have been devoted to discover suitable draw solutes. Qingchun et al. (2013), presented a comprehensive and critical review on the existing draw solutions and their applications in FO processes. Some of the many compounds proposed in the literature as draw solutes are: inorganic salts, ammonia and carbon dioxide and macromolecules (fructose, sucrose, fatty acid-polyethylene glycol). The most challenging task is to develop sustainable integrated systems for water production and draw solute recycle. Among the existing technologies for the draw solute recovery UF is one of the most promising because its low energy demand. Some authors have presented studies on FO desalination at pilot scale using thermal methods for the draw solute recovery (McGinnis et al., 2013). However, in the literature there is a lack of studies investigating the actual possibility of implementing an industrial scale system integrating the FO and UF technologies for a cost efficient desalination process. The aim of this work is to study the capabilities of an integrated FO/UF system, as a desalination technology alternative to RO.

\section{Problem statement}

The design problem is to address the optimal configuration of a superstructure-based hybrid membrane system for seawater desalination. The superstructure proposed comprises both, RO and FO, desalination units and a set of membrane filtration units in series (UF, NF). In a first stage, the exiting draw solution from the FO unit enters a UF unit. If necessary, the permeated stream would enter another UF or NF unit to recover the product water and concentrate the draw solution from the FO. The network includes also mixer and splitter units to distribute the streams allowing the alternative connections between the units that may enhance the performance of the system (Figure $1)$.

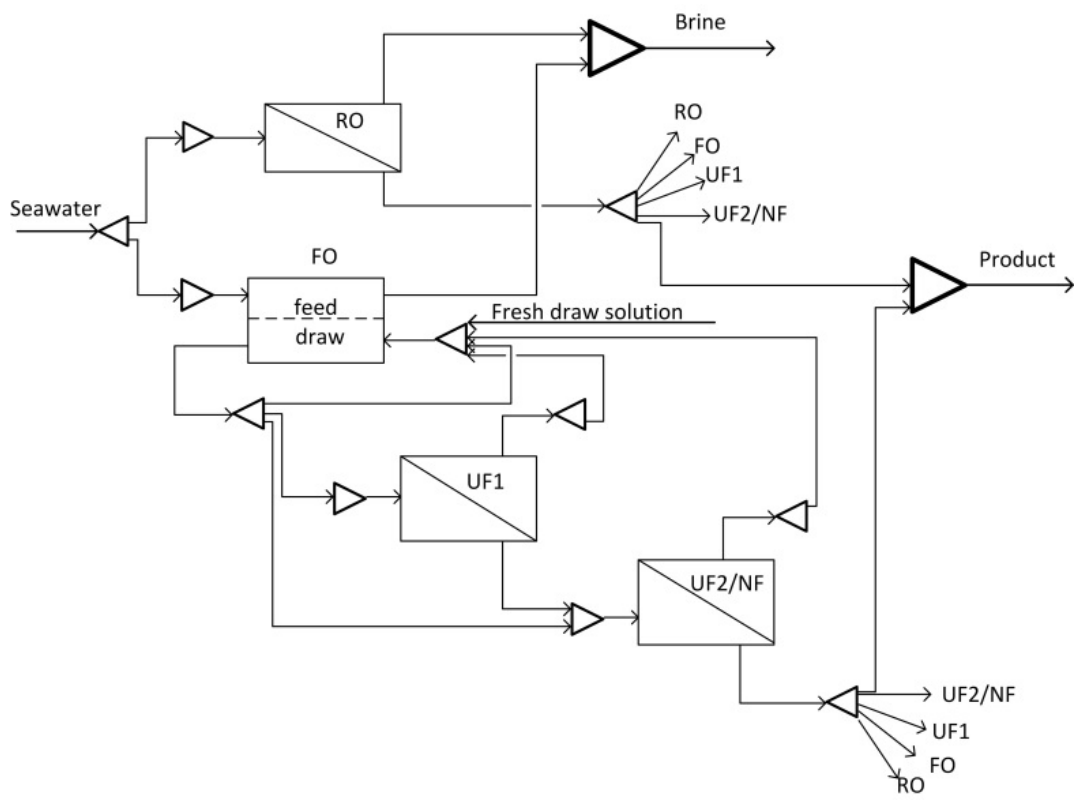

Figure 1. Superstructure for the hybrid membrane system proposed. 


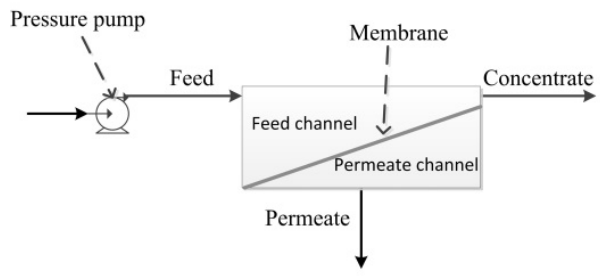

a)

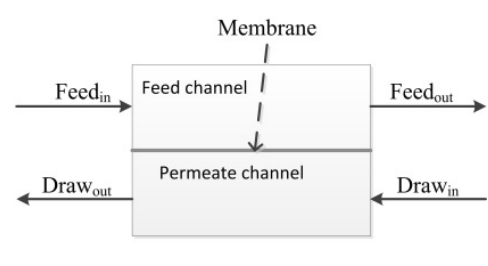

b)

Figure 2. Schemes of the process units: a) Membrane separation processes (RO, UF, NF); b) Forward Osmosis.

The superstructure must take into account also the different input/output topology of the FO unit with respect to the other membrane processes units, due to their different driving forces. The need of a draw solution in FO forces this unit to have two inlet streams unlike the other membrane units whose unique inlet is the pressurized feed stream. The schemes of both types of units are depicted in Figure 2.

The goal is to determine the optimal design of a seawater desalination plant that may use either one of the desalination technologies or both of them (hybrid system), to optimize its economic performance.

\section{Mathematical model}

We use the mathematical programming approach to calculate the optimal network configuration of the plant. This method has been successfully used for the design of optimal RO networks (Saif et al., 2008) and wastewater treatment plants including different types of treatment units (Galan and Grossmman, 2011).

Mass balances in all units and short-cut models describing the performance of the membrane processes lead to a non-linear programming (NLP) problem of the form

$$
\begin{array}{cl}
\min _{\mathbf{x}} & \{S T C(\mathbf{x})\} \\
\text { s.t. } & \mathbf{h}(\mathbf{x})=\mathbf{0} \\
& \mathbf{g}(\mathbf{x}) \leq \mathbf{0}
\end{array}
$$

where the objective is to minimize the specific total cost (STC, $\$ / \mathrm{m}^{3}$ of fresh water produced).

The environmental performance of the plant has also been assessed using the global warming potential (GWP, $\mathrm{kg} \mathrm{CO}_{2} / \mathrm{m}^{3}$ of fresh water produced) indicator as described by the IPCC 2007 (Intergovernmental Panel on Climate Change) (Hischier et al., 2007).

\subsection{Membrane processes models}

The membrane processes have been modeled according to their transport mechanism across the membrane. The transport in the desalination units occurs through a solutiondiffusion mechanism, while the other membrane processes are size exclusion filtrations.

In the following subsections, we detail the short-cut models used to describe the transport mechanism of each process.

\subsubsection{Desalination units}

The transport across the RO membrane is described through the osmotic pressure law

$F_{p}^{R O}=K_{m}^{R O} A_{m e m b}^{R O}(\Delta P-\Delta \pi)$ 
$F_{p}$ is the permeate flow, $A_{\text {memb }}$ is the total membrane area, $K_{m}$ is the membrane permeability, $\Delta \mathrm{P}$ is the pressure applied and $\Delta \pi$ is the osmotic pressure difference across the membrane. The design variables here are the membrane area $A_{\text {memb }}$ and the pressure applied $\Delta \mathrm{P}$.

For the FO process, as no pressure is applied, Eq. (2) is modified as follows

$F_{p}^{F O}=K_{m}^{F O} A_{\text {memb }}^{F O}\left(\pi_{d}-\pi_{f}\right)$

where $\pi_{\mathrm{d}}$ and $\pi_{\mathrm{f}}$ are the osmotic pressures of the draw and feed solutions, respectively. In this case the design variables are $\mathrm{A}_{\mathrm{memb}}$ and $\pi_{\mathrm{d}}$, which depends on the concentration of the draw solution.

Note that in these models the concentration polarization phenomenon has been neglected.

\subsubsection{Filtration units}

The only difference among the membrane filtration processes, UF and NF in this particular case, is the size of the solute removed from the feed stream. In this processes the transport across the membrane can be modeled using a modified Darcy's law

$$
F_{p}^{M}=\frac{\Delta P^{M}}{\mu R_{m}^{M}} A_{m e m b}^{M} ; \quad \forall M \in\{U F, N F\}
$$

$\mathrm{R}_{\mathrm{m}}$ is the resistance of the membrane to the pass of water and $\mu$ is the dynamic viscosity of water. The design variables are also $\mathrm{A}_{\text {memb }}$ and the $\Delta \mathrm{P}$.

\subsection{Objective function}

The objective function is the specific total cost (STC). The cost terms include the annualized investment cost (IC), which is mainly the cost of the membrane modules, the operation and maintenance of the membranes (O\&M) and the cost of the electricity required for the entire system.

$S T C=\frac{\sum_{\text {memb }} I C+\sum_{\text {memb }}(O \& M)+\text { Elect }}{F_{\text {product }}}$

\section{Case study}

The proposed model has been applied to the design of a medium-size seawater desalination plant with a given production of $50 \mathrm{~kg} / \mathrm{s}$ of fresh water. It is assumed that the plant operates during $24 \mathrm{~h} / \mathrm{d}$. For the FO process a polyglycol polymer was selected as draw solute.

\section{Results and discussion}

The model has been implemented in GAMS and solved to global optimality using the solver BARON, version 9.0.6. The results show that the minimum specific cost is achieved when both desalination technologies (RO and FO) are used together (Figure 3 ). In the economically most efficient configuration of the network, the total seawater flow rate treated in the plant is split into two streams; almost the $70 \%$ is treated in the RO unit and the rest in the FO unit. 


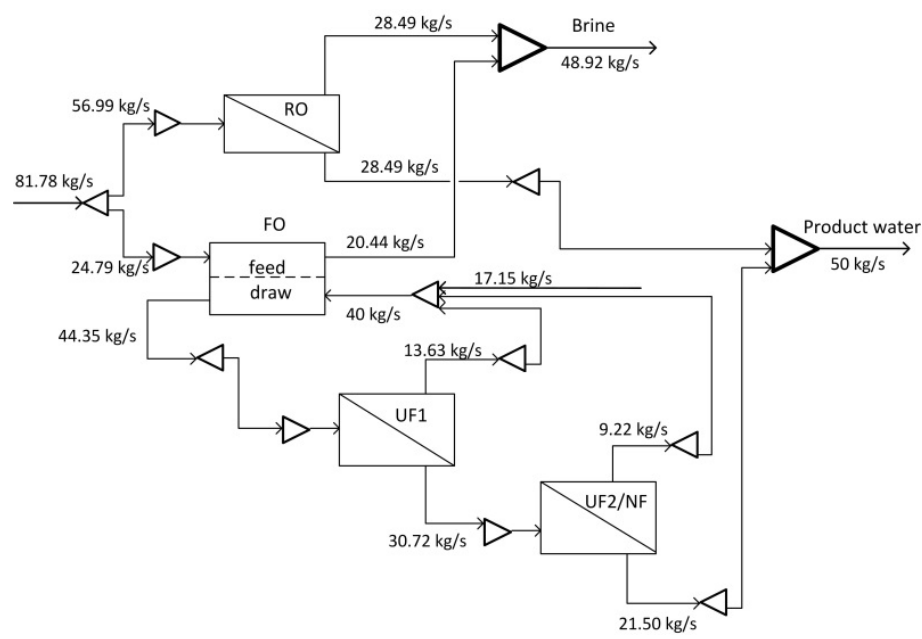

Figure 3. Optimal configuration of the network.

The system was also solved with some structural variables of the network fixed, in order to enforce the plant to operate either using only RO or only FO. In Figure 4 the economical and environmental performances of these three configurations are compared.When the plant operates using the hybrid membrane system, the cost is reduced $16 \%$ with respect to the cost of the RO plant and $45 \%$ with respect to the FO plant. Regarding the environmental indicator, the hybrid system shows a worse performance than the FO plant, but it is enhanced in more than $30 \%$ with respect to the RO plant. In this latter case the greenhouse gas emissions are so significant due to the great amount of electricity required by the RO. On the contrary, when FO is the only desalination technology used, these emissions are highly reduced due to the reduction on the electricity consumption, while the total cost is increased due to the high investment and maintenance cost of the membranes. Note that these calculations consider only the desalination part of the plant. We assume that other processes involving pre and post treatments, are the same regardless the desalination technology used.

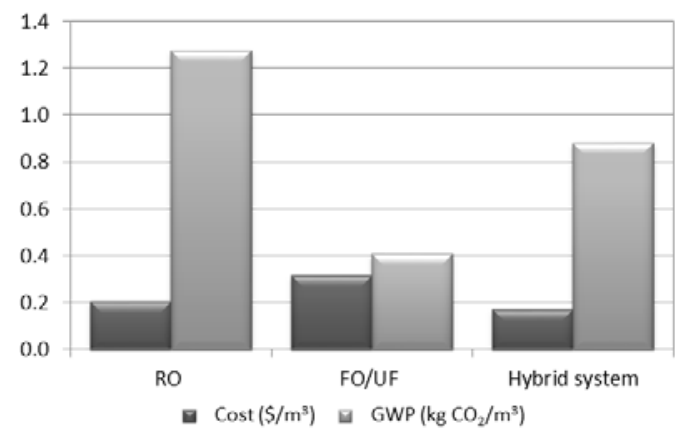

Figure 4. Comparison between the performances of the three desalination plant configurations.

The cost breakdown of the compared configurations, which is depicted in Figure 5, shows the higher cost of the electricity when only RO is used and the higher investment cost when only FO is used. 
Cost breakdown RO process

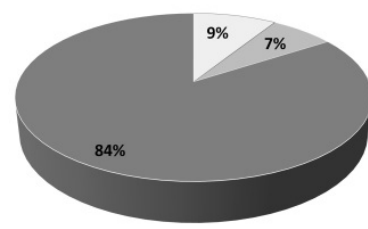

$\square$ ICost $=$ O\&M $=$ Electricity
Cost breakdown FO process

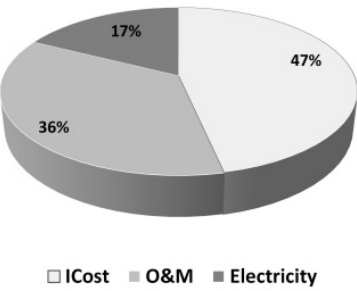

Cost breakdown hybrid process

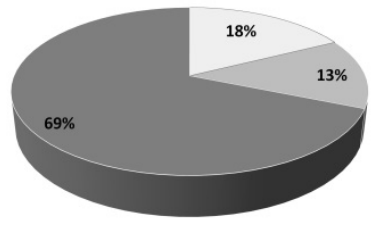

$\square$ ICost $=0 \& M \quad=$ Electricity

Figure 5. Cost breakdown of the three plant configurations.

\section{Conclusions}

A superstructure-based hybrid membrane desalination system using reverse and forward osmosis has been proposed for the synthesis of the economical most efficient plant. The membrane processes have been described using short-cut models. The design problem has been illustrated through a case study of a seawater desalination plant with a given production. The results highlight that, at the current state of development of the FO technology, it cannot totally replace the RO technology due to its high investment cost. A better solution to improve simultaneously the environmental and economic performance of seawater desalination plants, is to integrate both technologies in the desalination process.

\section{Acknowledgements}

The authors wish to acknowledge support from the Spanish Ministry of Education and Science (CTQ2012-37039-C02-02) and the University of Alicante (GRE11-19).

\section{References}

T.S. Chung, X. Li, R.C. Ong, Q. Ge, H.L. Wang, G. Han, 2012a, Emerging forward osmosis (FO) technologies and challenges ahead for clean water and clean energy applications, Curr. Opinion Chem. Eng.,1, 1246-257.

T.S. Chung, S. Zhang, K.Y. Wang, J.C. Su, M.M. Ling, 2012b, Forward osmosis processes: yesterday, today and tomorrow, Desalination, 287, 78-81.

B. Galan, I.E. Grossmann, 2011, Optimal design of real world industrial wastewatertreatment networks, Computer Aided Chemical Engineering, 29, 1251-1255.

R. Hischier, W. Beidema, H.-J. Althaus, C. Bauer, G. Doka, R. Dones, R. Frischknecht, S. Hellweg, S. Humbert, N. Jungbluth, T. Köllner, Y. Loerincik, M. Margni, T. Nemecek, 2010, Implementation of Life Cycle Impact Assessment Methods. Final report ecoinvent v2.2 in, Swiss Centre for Life, Dübendorf, Switzerland.

R.L. McGinnis, N.T. Hancock, M.S. Nowosielski-Slepowron, G.D. McGurgan, 2013, Pilot demonstration of the $\mathrm{NH} 3 / \mathrm{CO} 2$ forward osmosis desalination process on high salinity brines, Desalination, 312, 67-74.

N. Nirmalakhandan, S. Deng, V.G. Gude, 2010, Renewable and sustainable approaches for desalination, Renew. Sustain. Energy Rev., 14, 9, 2641-2654.

Q. Ge, M. Ling, T.-S. Chung, 2013, Draw solutions for forward osmosis processes: Developments, challenges, and prospects for the future, Journal of Membrane Science, 442, 225-237.

Y. Saif, A.Elkamel, M. Pritzker, 2008, Optimal design of reverse-osmosis networks for wastewater treatment, Chemical Engineering and Processing: Process Intensification, 47, 2163 -2174 . 